\title{
Egg yolk in the eye: an ultrawide field evaluation
}

\author{
Koushik Tripathy, Rohan Chawla, Kanhaiya Mittal, Shreyas Temkar
}

Department of Retina and Uvea, Dr. Rajendra Prasad Centre for Ophthalmic Sciences, All India Institute of Medical Sciences, New Delhi, India

\section{Correspondence to} Dr Koushik Tripathy, koushiktripathy@gmail.com

Accepted 13 January 2016

\section{DESCRIPTION}

A 35-year-old man presented with gradual onset dimness of vision in both eyes noted for 3 years. The anterior segment, intraocular pressures and pupillary reactions were unremarkable in both the eyes. Best corrected visual acuity in both eyes was $6 / 18$. The fundus showed a subretinal oval, smooth yellowish lesion $3 \times 2$ disc diameters in size at the macula in either eye simulating an 'egg yolk', with temporal white without pressure (WWOP) in either eye (figure 1A). Ultrawide field autofluorescence (Optos Inc, Marlborough, Massachusetts, USA) demonstrated brilliant autofluorescence corresponding to the subretinal lesion (figure 1B). Spectral domain optical coherence tomography (Cirrus HD-OCT, Carl Zeiss Meditec, Dublin, California, USA) showed a collection of hyperreflective material creating a mound at the macula (figure 1C). The inner-segment-outer segment junction (photoreceptor inner segment ellipsoid line) ${ }^{1}$ was discontinuous at the fovea, possibly explaining the visual deficit in both eyes. ${ }^{2}$ The ultrawide field fluorescein angiogram showed blockage of choroidal fluorescence at the egg yolk lesion without any evidence of leakage. Window defects were evident bilaterally in the temporal periphery (figure 2A). The Goldmann visual field showed a central scotoma correlating to the egg yolk lesion (figure 2B). The Arden ratio on electrooculography (EOG) was $140 \%$ in the right eye and $133 \%$ in the left eye, confirming the diagnosis of Best vitelliform macular dystrophy.

Best disease is an autosomal dominant dystrophy. The vitelliform stage of the disease is characterised by a drastic fundus appearance of subretinal egg yolk with minimal or no visual compromise. EOG is typically abnormal. The accumulated material (lipofuscin) is brilliantly autofluorescent. Ultrawide field imaging uses a scanning laser ophthalmoscope with optics of an ellipsoid mirror to provide a single image of $200^{\circ}$, or $82 \%$ of the retina. ${ }^{3}$ The ultrawide field imaging also picked up peripheral WWOP and mild window defects on the fluorescein angiogram. Ultrawide field imaging often picks up peripheral retinal abnormalities in diseases that are clinically defined by macular involvement.

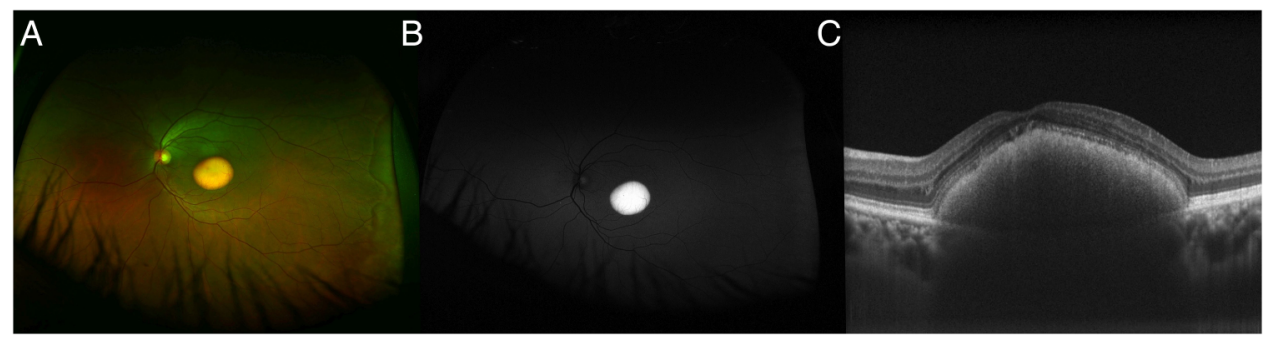

Figure 1 (A) Ultrawide field fundus pseudo-colour image (Optos Inc, Marlborough, Massachusetts, USA) of left eye shows subretinal oval, smooth egg yolk-like yellowish lesion with regular margins at macula, with temporal white without pressure (WWOP). (B) Ultrawide field autofluorescence (Optos Inc, Marlborough, Massachusetts, USA) reveals brilliant autofluorescence corresponding with the subretinal macular lesion. (C) Spectral domain optical coherence tomography (Cirrus HD-OCT, Carl Zeiss Meditec, Dublin, California, USA) showed a collection of hyper-reflective material creating a mound at the macula.

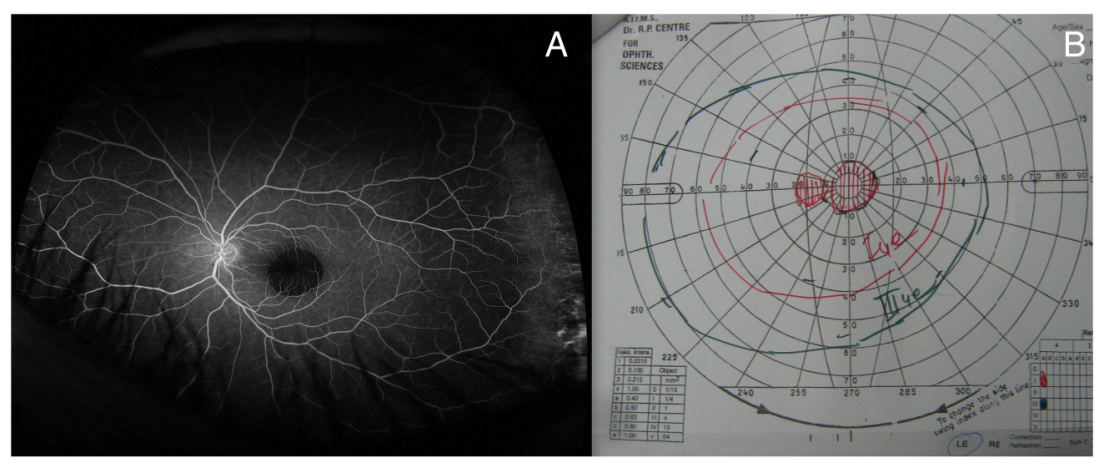

Figure 2 (A) The ultrawide field fluorescein angiogram showed blockage of choroidal fluorescence at the egg yolk lesion, with no evidence of leakage, and window defects at the temporal periphery. (B) The Goldmann visual field showed a central scotoma correlating with the egg yolk lesion along with the blind spot. 
Learning points

- Vitellifom stage of best disease is characterised by an egg yolk lesion at the macula, which is brilliantly autofluorescent.

- Ultrawide field imaging captures $200^{\circ}$ of the retina and picks up central as well as peripheral retinal disorders in a single image.

Contributors KT and RC had full access to all of the data in the study, and took responsibility for the integrity of the data and the accuracy of the data analysis. KT and $\mathrm{KM}$ were involved in the acquisition of data. KT and ST were involved in the analysis and interpretation of data. All the authors were involved in the drafting of the manuscript, critical revision of the manuscript for important intellectual content and, study concept and design. RC was involved in the administrative, technical or material support: RC was involved in the study supervision.

Competing interests None declared.

\section{Patient consent Obtained.}

Provenance and peer review Not commissioned; externally peer reviewed.

\section{REFERENCES}

1 Spaide RF, Curcio CA. Anatomical correlates to the bands seen in the outer retina by optical coherence tomography: literature review and model. Retina 2011;31:1609-19.

2 Querques G, Regenbogen M, Quijano C, et al. High-definition optical coherence tomography features in vitelliform macular dystrophy. Am J Ophthalmol 2008;146:501-7.

3 Tripathy K, Sharma YR, Gogia V, et al. Serial ultra wide field imaging for following up acute retinal necrosis cases. Oman J Ophthalmol 2015;8:71-2.

Copyright 2016 BMJ Publishing Group. All rights reserved. For permission to reuse any of this content visit http://group.bmj.com/group/rights-licensing/permissions.

BMJ Case Report Fellows may re-use this article for personal use and teaching without any further permission.

Become a Fellow of BMJ Case Reports today and you can:

- Submit as many cases as you like

- Enjoy fast sympathetic peer review and rapid publication of accepted articles

- Access all the published articles

- Re-use any of the published material for personal use and teaching without further permission

For information on Institutional Fellowships contact consortiasales@bmjgroup.com

Visit casereports.bmj.com for more articles like this and to become a Fellow 